\title{
Triagem de genótipos de hortaliças para resistência a Meloidogyne enterolobii
}

\author{
Osvânder David de Melo(1), Wilson Roberto Maluf(1), Ranoel José de Sousa Gonçalves ${ }^{(1)}$, \\ Álvaro Carlos Gonçalves Neto(1), Luiz Antonio Augusto Gomes ${ }^{(1)}$ e Regis de Castro Carvalho ${ }^{(1)}$ \\ (1)Universidade Federal de Lavras, Departamento de Agricultura, Caixa Postal 3037, CEP $37200-000$ Lavras, MG. \\ E-mail: osmelo2000@yahoo.com.br, wrmaluf@dag.ufla.br, ranoelgoncalves@hotmail.com, alvarocgneto@gmail.com, laagomes@ufla.br, \\ regisccarvalho@hotmail.com
}

\begin{abstract}
Resumo - O objetivo deste trabalho foi identificar genótipos de alface, batata-doce, feijão, tomate e Capsicum resistentes ao nematoide Meloidogyne enterolobii (Syn. M. mayaguensis) e classificá-los quanto ao grau de resistência. Foram avaliados: 10 genótipos de alface, 8 de batata-doce, 10 de feijão e feijão-vagem, 25 de Capsicum e 6 de tomate. Foram calculados o fator de reprodução e o índice de reprodução, e os genótipos foram classificados quanto ao grau de resistência ao nematoide. Foram observados níveis moderados de resistência na cultivar de feijão Aporé e nos acessos de pimenta, BGH-433 e BGH-4285, e de pimentão, PIM-031, PIX-022I-31-07-02 e PIX-022I-31-13-01. Todos os genótipos de tomate são suscetíveis a M. enterolobii. As cultivares de alface Julia, Hortência, Verônica, Grand Rapids e Babá de Verão, e os clones de batata-doce UFLA07-49 e UFLA07-53 são muito resistentes ao nematoide. A resistência a M. enterolobii aparentemente é mediada por genes diferentes dos que conferem resistência a outras espécies e raças de Meloidogyne.
\end{abstract}

Termos para indexação: Meloidogyne mayaguensis, fator de reprodução, índice de reprodução.

\section{Screening vegetable crop species for resistance to Meloidogyne enterolobii}

\begin{abstract}
The objective of this work was to identify genotypes of lettuce, sweet potato, bean, tomato, and Capsicum resistant to the nematode Meloidogyne enterolobii (Syn. M. mayaguensis), and to classify them according to their resistance degree. The following were evaluated: 10 genotypes of lettuce, 8 of sweet potato, 10 of bean and snap bean, 25 of Capsicum, and 6 of tomato genotypes. Reproduction factor and reproduction index were determined, and genotypes were classified according to their resistance degree to the nematode. Moderate levels of resistance were observed in the bean cultivar Aporé and in the accessions of pepper BGH-433 and BGH-4285, and of sweet pepper, PIM-031, PIX-022I-31-07-02, and PIX-022I-31-13-01. All tomato genotypes are susceptible to M. enterolobii. Lettuce cultivars Julia, Hortência, Verônica, Grand Rapids and Babá de Verão, and sweetpotato clones UFLA07-49 and UFLA07-53 are very resistant to the nematode. Apparently, the resistance to $M$. enterolobii is controlled by different genes from the ones which confer resistance to other species and races of Meloidogyne.
\end{abstract}

Index terms: Meloidogyne mayaguensis, reproduction factor, reproduction index.

\section{Introdução}

Nematoides são parasitas obrigatórios de plantas que podem causar vários danos diretos aos órgãos subterrâneos de algumas hortaliças (raízes, rizomas, tubérculos e bulbos), ao introduzir seu aparelho bucal na parede celular e ao movimentar-se no interior das células do hospedeiro (Campos et al., 2001).

Atualmente, uma espécie de menor conhecimento, Meloidogyne enterolobii (Syn. M. mayaguensis) (Yang \& Eisenback, 1983), tem ganhado importância, pois fontes de resistência efetivas contra outros nematoides, como $M$. javanica, $M$. arenaria e $M$. incognita, são ineficazes no seu controle (Carneiro et al., 2006a). No Brasil, a espécie $M$. enterolobii foi identificada pela primeira vez em 1988, nos municípios de Petrolina, PE, e Curaçá e Maniçoba, BA, tendo causado danos severos em plantios comerciais de goiabeira (Psidium guajava L.) (Carneiro et al., 2006b).

$\mathrm{Na}$ literatura, são inúmeros os relatos de plantas descritas como resistentes a outras espécies de nematoides-das-galhas e suscetíveis a $M$. enterolobii. Cantu et al. (2009), ao avaliar a resistência a $M$. enterolobii de oito porta-enxertos de tomate

Pesq. agropec. bras., Brasília, v.46, n.8, p.829-835, ago. 2011 
considerados resistentes a $M$. incognita, $M$. javanica e $M$. arenaria, observaram que os porta-enxertos mostraram-se suscetíveis a $M$. enterolobii. Um teste de parasitismo desse nematoide realizado em diferentes espécies vegetais mostrou que o feijão (Phaseolus vulgaris) 'IPA-9', o feijão-caupi 'IPA-206' e as cultivares de tomate Santa Cruz e Viradoro foram suscetíveis (Guimarães et al., 2003). Oliveira (2007) relatou que, em Capsicum spp., somente a espécie $C$. frutescens foi considerada resistente a M. enterolobii. Contudo, ao analisar a compatibilidade para enxertia com cultivares comerciais de pimentão suscetíveis, o autor verificou que $C$. frutescens foi o único genótipo que apresentou incompatibilidade. Bitencourt \& Silva (2010) classificaram as cultivares Mônica, de alface crespa, e Grandes Lagos 659, de alface americana, como muito resistentes a $M$. enterolobii. No entanto, ainda são escassos os estudos sobre os efeitos da infestação de $M$. enterolobii em alface, embora essa cultura seja, em geral, vulnerável ao ataque de nematoides, com alguns genótipos resistentes a $M$. incognita e M. javanica (Gomes et al., 2000; Maluf et al., 2002; Carvalho Filho et al., 2008; Silva et al., 2008). Neste contexto, a resistência genética em plantas, sempre que disponível, tem sido a forma mais eficiente e econômica de controle dos nematoides-das-galhas.

O objetivo deste trabalho foi identificar genótipos de alface, batata-doce, feijão, tomate e Capsicum resistentes ao nematoide Meloidogyne enterolobii e classificá-los quanto ao grau de resistência.

\section{Material e Métodos}

O experimento foi conduzido em estufas, e as avaliações foram realizadas no Laboratório de Nematologia do Departamento de Fitopatologia, da Universidade Federal de Lavras (Ufla), Lavras, MG, em setembro de 2010. Foram avaliados: seis genótipos de tomate - dois da espécie Solanum lycopersicum (Syn. Lycopersicon esculentum) (TOM-584 e TOM-684), dois de Solanum habrochaites (Syn. Lycopersicon hirsutum) (PI-127826 e PI-134417), um de Solanum pennellii (Syn. Lycopersicon pennellii) (LA-716) e um de Solanum peruvianum (Syn. Lycopersicon peruvianum) (PI-126443); dez cultivares de alface (Elisa, Julia, Luisa, Hortência, Mirella, Vera, Verônica, Grand Rapids, Salinas 88 e Babá de Verão); dez cultivares de feijão e feijão-vagem (Aporé, Talismã,
Ouro Negro, Macarrão Atibaia, Macarrão Favorito, Macarrão Preferido, Macarrão Rasteiro, Macarrão Rasteiro Conquista, Macarrão Rasteiro Dourado e Macarrão Trepador); oito genótipos de batata-doce Ipomoea batatas (UFLA07-31, UFLA07-43, UFLA07-49, UFLA07-53, 'Brazlândia Branca', 'Brazlândia Rosada', 'Brazlândia Roxa' e 'Palmas'); e 25 genótipos de pimenta ou pimentão Capsicum (os acessos de C. annuum 'Ikeda', 'Magali-R', 'Magnata Super', 'Mayara F1', PIM-030, PIM-031, PIM-032, PIM-033, PIM-034, PIM-035, PIM-036, PIM-037, Linha-017, PIX-022I-31-07-01, PIX-022I-31-07-02, PIX-022I-31-13-01, PIX-02 I-31-13-02, PIX-022I-31-14-01, PIX-022I-31-14-02, PIX-022I-31-20-01, PIX-022I-31-20-02, 'Carolina Wonder' e 'Charleston Belle', bem como os acessos de $C$. chinense BGH-433 e BGH-4285).

As linhagens de tomate TOM-584 e TOM-684 foram utilizadas nos experimentos de alface, feijão, feijão-vagem, pimentão, pimenta e tomate como padrões de suscetibilidade e resistência a Meloidogyne (M. incognita e $M$. javanica), enquanto a cultivar de tomateiro Santa Clara foi utilizada como padrão suscetível, no experimento de batata-doce. Os experimentos de alface, tomate e Capsicum foram realizados em bandejas de poliestireno de 128 células contendo substrato Plantimax (Eucatex, Paulínia, SP). Utilizou-se o delineamento inteiramente casualizado, com duas repetições contendo oito plantas cada uma. No experimento de feijão, foram semeadas duas sementes por vaso de $500 \mathrm{~mL}$ contendo substrato Plantimax e, logo após a germinação, foi feito o desbaste, tendo-se deixado uma planta por vaso. Foi utilizado o delineamento experimental inteiramente casualizado, com 16 plantas por tratamento, sendo cada planta uma repetição. $\mathrm{O}$ experimento de batata-doce foi conduzido em bandejas de 72 células, em delineamento inteiramente casualizado, com duas repetições contendo seis plântulas cada uma, obtidas pelo plantio de ramas de quatro gemas internodais.

Utilizou-se, como fonte de inóculo, uma população de $M$. enterolobii previamente multiplicada e mantida em casa de vegetação, em plantas de tomate TOM-684 cultivadas em vaso. A extração dos ovos foi feita de acordo com o método de Hussey \& Barker (1973), modificado por Bonetti \& Ferraz (1981). As raízes de tomate contendo galhas foram cortadas em pedaços de aproximadamente $0,5 \mathrm{~cm}$ de comprimento e trituradas em liquidificador durante $40 \mathrm{~s}$, com solução 
de hipoclorito de sódio a $0,5 \%$. Em seguida, a solução contendo os ovos foi vertida em peneira de malha com abertura de $0,074 \mathrm{~mm}$, sobre peneira de malha com $0,028 \mathrm{~mm}$, e os ovos foram submetidos à completa lavagem em água corrente. Os ovos retidos na peneira de malha menor foram coletados e quantificados em microscópio.

As plantas de alface, tomate, feijão e Capsicum foram inoculadas 15 dias após a semeadura, com uso de seringa automática de uso veterinário. Nos experimentos de alface e tomate, foi utilizada uma alíquota de solução contendo 3.360 ovos (população inicial) por planta e, no experimento de feijão, uma alíquota de 10.080 ovos por vaso. A viabilidade do inóculo foi quantificada por meio de câmaras de eclosão. Como o inóculo utilizado nos experimentos de alface, tomate e feijão apresentou viabilidade de $59,3 \%$, a quantidade de ovos viáveis inoculados em cada planta de tomate e alface foi de 1.992 ovos e, em feijão, de 5.977 ovos. No experimento com Capsicum, foram inoculados 828 ovos viáveis por planta. Já no experimento de batata-doce, foram inoculados 2.065 ovos viáveis por plântula, aos 30 dias após o plantio. Foram realizadas irrigações diárias das mudas até a ocasião das avaliações, iniciadas 60 dias após as inoculações, quando o sistema radicular de cada planta foi cortado com tesoura e, em seguida, triturado em liquidificador, conforme a técnica de Hussey \& Barker (1973), modificada por Bonetti \& Ferraz (1981). Em seguida, foi feita contagem do número total de ovos da população final, tendo-se utilizado câmara de Peters e microscópio estereoscópico. O número de ovos por grama de raiz foi calculado pela divisão do número de ovos pelo peso fresco de raiz.

O fator de reprodução (FR) foi determinado pela divisão do número de ovos viáveis da população final pelo número da população inicial. $\mathrm{O}$ valor do índice de reprodução (IR\%) foi calculado pela fórmula: 100(número de ovos por grama de raiz de cada repetição/ número médio de ovos por grama de raiz das plantas da testemunha suscetível TOM-584). De acordo com o critério estabelecido por Taylor (1967), o grau de resistência foi classificado como: S, suscetível, com IR superior a $50 \%$ do valor obtido para o tomate TOM-584; LR, levemente resistente, com IR de 26 a 50\%; MoR, moderadamente resistente, com IR de 11 a $25 \%$; MR, muito resistente, com IR de 1 a $10 \%$; AR, altamente resistente, com IR menor que $1 \%$; e I, imune, quando não houve reprodução. Os dados foram transformados pela equação $\log (\mathrm{x}+1)$ e, em seguida, submetidos à análise de variância, tendo-se utilizado o SAS Institute (2001). Quando significativas, as médias foram comparadas pelo teste de Duncan, a $5 \%$ de probabilidade.

\section{Resultados e Discussão}

Foram observadas diferenças significativas entre os genótipos com relação ao FR e ao IR, o que confirma a existência de variabilidade genética para a resistência a $M$. enterolobii. No entanto, embora tenha havido diferenças significativas entre os tratamentos (Tabela 1), todos os acessos de tomate foram classificados como suscetíveis, conforme a escala de Taylor (1967). Apesar da linhagem TOM-684 ser portadora do gene dominante $M i$, que confere resistência às espécies $M$. incognita, $M$. arenaria e M. javanica (Williamson, 1998), a resistência não foi efetiva para $M$. enterolobii, como observado por Carneiro et al. (2006b) e Cantu et al. (2009). O acesso $S$. peruvianum PI-126443, portador do gene $M i$ e do gene $M i-3$, que confere resistência a $M$. incognita sob altas temperaturas (Devran et al., 2010), também mostrou-se bastante suscetível a $M$. enterolobii. Os acessos selvagens PI-134417 (S. habrochaites var. glabratum), PI-127826 (S. habrochaites var. hirsutum) e LA-716 ( $S$. pennellii) apresentaram índices de reprodução acima de $150 \%$, o que os caracteriza como ótimos hospedeiros para $M$. enterolobii. Os resultados obtidos indicam que nem o gene $M i$, presente em diversas cultivares e porta-enxertos comerciais de tomate, nem o gene $\mathrm{Mi}-3$, considerado promissor para o controle de Meloidogyne em condições de alta temperatura do solo (Devran et al., 2010), são efetivos no controle de $M$. enterolobii. No entanto, alguns genótipos de tomate foram considerados resistentes ao nematoide, em trabalhos recentes. Pinheiro et al. (2009), ao avaliar o índice de galhas em 83 acessos do Banco de Germoplasma da Embrapa Hortaliças, concluíram que 18 acessos apresentaram resistência moderada, enquanto um acesso, CNPH-1543, foi altamente resistente a $M$. enterolobii.

Nas cultivares de feijão, a maioria dos tratamentos foi considerada suscetível, com índices de reprodução maiores que 50\% (Tabela 1). Apenas a cultivar Aporé apresentou algum nível de resistência, tendo sido classificada como levemente resistente. Essa cultivar foi descrita (Ferreira et al., 2010) como muito resistente a $M$. javanica, levemente resistente a $M$. incognita 
raça 1 e moderadamente resistente a $M$. incognita raça 3. Entre as cultivares consideradas suscetíveis a M. enterolobii, Macarrão Atibaia e Macarrão Favorito apresentaram os menores índices de reprodução e não diferiram significativamente entre si. De acordo com a literatura, essas cultivares apresentam níveis satisfatórios de resistência a $M$. javanica e $M$. incognita raças 1 e 3 (Ferreira et al., 2010). As cultivares Talismã e Ouro Negro, também com níveis de resistência a $M$. javanica e $M$. incognita raças 1 e 3 (Ferreira et al., 2010), mostraram-se bastante suscetíveis a M. enterolobii, com IR $>100 \%$. Embora a resistência das cultivares Aporé, Macarrão Atibaia e Macarrão Favorito descrita na literatura para $M$. javanica e

Tabela 1. Fator de reprodução (FR), índice de reprodução (IR), e grau de resistência (GR) de Meloidogyne enterolobii em tomate, feijão alface, batata-doce e Capsicum ${ }^{(1)}$.

\begin{tabular}{|c|c|c|c|}
\hline Tratamento & Fator de reprodução (\%) & Índice de reprodução (\%) & Grau de resistência ${ }^{(2)}$ \\
\hline & \multicolumn{3}{|c|}{ Experimento de tomate } \\
\hline Tomate TOM-584(3) & $7,0 \mathrm{~b}$ & $100,0 \mathrm{~b}$ & S \\
\hline Tomate TOM-684(4) & $5,2 \mathrm{a}$ & $74,5 \mathrm{a}$ & S \\
\hline PI-126443 (Lycopersicon peruvianum) & $13,2 \mathrm{c}$ & $188,6 \mathrm{c}$ & S \\
\hline PI-127826 (L. hirsutum var. hirsutum) & $11,8 \mathrm{c}$ & $167,5 \mathrm{c}$ & S \\
\hline PI-134417 (L. hirsutum var. glabratum) & $18,4 \mathrm{~d}$ & $261,0 \mathrm{~d}$ & S \\
\hline \multirow[t]{2}{*}{ LA-716 (L.pennellii) } & $17,3 \mathrm{~d}$ & $246,3 \mathrm{~d}$ & $\mathrm{~S}$ \\
\hline & \multicolumn{3}{|c|}{ Experimento de feijão } \\
\hline Tomate TOM-584(3) & $3,6 \mathrm{c}$ & $100,0 \mathrm{c}$ & S \\
\hline Tomate TOM- $684^{(4)}$ & $11,1 \mathrm{f}$ & $309,6 \mathrm{f}$ & $\mathrm{S}$ \\
\hline 'Aporé' & $1,4 \mathrm{a}$ & $39,3 \mathrm{a}$ & LR \\
\hline 'Ouro Negro' & $7,2 \mathrm{~d}$ & $201,9 d$ & S \\
\hline 'Talismã' & $7,1 \mathrm{~d}$ & $197,0 \mathrm{~d}$ & S \\
\hline 'Macarrão Atibaia' & $2,2 b$ & $61,6 b$ & S \\
\hline 'Macarrão Favorito' & $2,1 b$ & $59,0 \mathrm{~b}$ & S \\
\hline 'Macarrão Preferido' & $17,2 \mathrm{~g}$ & $478,5 \mathrm{~g}$ & S \\
\hline 'Macarrão Rasteiro' & $9,5 \mathrm{e}$ & $264,8 \mathrm{e}$ & S \\
\hline 'Macarrão Rasteiro Conquista' & $6,5 \mathrm{~d}$ & $182,1 \mathrm{~d}$ & S \\
\hline 'Macarrão Rasteiro Dourado' & $16,9 \mathrm{~g}$ & $470,1 \mathrm{~g}$ & S \\
\hline \multirow[t]{2}{*}{ 'Macarrão Trepador' } & $16,3 \mathrm{~g}$ & $454,4 \mathrm{~g}$ & $\mathrm{~S}$ \\
\hline & \multicolumn{3}{|c|}{ Experimento de alface } \\
\hline Tomate TOM-584(3) & $7,3 \mathrm{j}$ & $100,0 \mathrm{j}$ & S \\
\hline Tomate TOM- $684^{(4)}$ & $4,7 \mathrm{i}$ & $64,1 \mathrm{i}$ & S \\
\hline 'Elisa' & $0,8 \mathrm{e}$ & $12,0 \mathrm{de}$ & MoR \\
\hline 'Julia' & $0,7 \mathrm{~d}$ & $10,3 \mathrm{~d}$ & MR \\
\hline 'Hortência' & $0,2 \mathrm{ab}$ & $3,2 b$ & MR \\
\hline 'Luisa' & $1,1 \mathrm{fg}$ & $15,2 \mathrm{fg}$ & MoR \\
\hline 'Mirella' & $1,3 \mathrm{~h}$ & $18,1 \mathrm{~h}$ & MoR \\
\hline 'Vera' & $1,2 \mathrm{gh}$ & $17,0 \mathrm{gh}$ & MoR \\
\hline 'Verônica' & $0,1 \mathrm{a}$ & $2,3 a$ & MR \\
\hline 'Grand Rapids' & $0,2 b$ & $3,5 b$ & MR \\
\hline 'Salinas 88' & $1,0 \mathrm{f}$ & $13,8 \mathrm{ef}$ & MoR \\
\hline \multirow[t]{2}{*}{ 'Babá de Verão' } & $0,4 \mathrm{c}$ & $6,0 \mathrm{c}$ & MR \\
\hline & \multicolumn{3}{|c|}{ Experimento de batata-doce } \\
\hline Tomate cv. Santa Clara ${ }^{(3)}$ & $4,8 \mathrm{c}$ & $100,0 \mathrm{~d}$ & S \\
\hline UFLA07-31 & $2,2 b$ & $46,7 \mathrm{c}$ & LR \\
\hline UFLA07-43 & $3,4 \mathrm{c}$ & $71,7 \mathrm{~d}$ & S \\
\hline UFLA07-49 & $0,2 \mathrm{a}$ & $5,0 \mathrm{~b}$ & MR \\
\hline UFLA07-53 & $0,1 \mathrm{a}$ & $2,5 \mathrm{a}$ & MR \\
\hline 'Brazlândia Branca' & $10,6 \mathrm{~d}$ & $220,8 \mathrm{~d}$ & S \\
\hline 'Brazlândia Rosada' & $4,6 c$ & $95,9 d$ & S \\
\hline 'Brazlândia Roxa' & $7,0 \mathrm{~d}$ & $144,8 \mathrm{~d}$ & S \\
\hline 'Palmas' & $9,1 \mathrm{~d}$ & $189,2 \mathrm{~d}$ & $\mathrm{~S}$ \\
\hline
\end{tabular}


Tabela 1. Continuação.

\begin{tabular}{|c|c|c|c|}
\hline Tratamento & Fator de reprodução (\%) & Índice de reprodução (\%) & Grau de resistência $^{(2)}$ \\
\hline & \multicolumn{3}{|c|}{ Experimento de Capsicum } \\
\hline Tomate TOM-584 $4^{(3)}$ & $5,5 \mathrm{n}$ & $100,0 \mathrm{~m}$ & S \\
\hline Tomate TOM-684 $4^{(4)}$ & $9,0 \mathrm{o}$ & $164,6 n$ & S \\
\hline 'Ikeda' & $2,6 \mathrm{gh}$ & $48,4 \mathrm{gh}$ & LR \\
\hline 'Magali-R' & $3,8 \mathrm{k}$ & $70,4 \mathrm{k}$ & $\mathrm{S}$ \\
\hline 'Magnata Super' & $4,7 \mathrm{~m}$ & 85,01 & S \\
\hline 'Mayara F1' & $4,3 \mathrm{klm}$ & $78,0 \mathrm{kl}$ & S \\
\hline BGH-433 & $1,2 \mathrm{c}$ & $22,5 \mathrm{c}$ & MoR \\
\hline BGH-4285 & $1,0 \mathrm{~b}$ & $18,9 \mathrm{~b}$ & MoR \\
\hline PIM-030 & $2,3 \mathrm{~g}$ & $43,2 \mathrm{~g}$ & LR \\
\hline PIM-031 & $1,0 \mathrm{bc}$ & $19,7 \mathrm{~b}$ & MoR \\
\hline PIM-032 & $2,9 \mathrm{hi}$ & $53,1 \mathrm{hi}$ & S \\
\hline PIM-033 & $2,9 \mathrm{hi}$ & $53,1 \mathrm{hi}$ & S \\
\hline PIM-034 & $2,9 \mathrm{hi}$ & $52,9 \mathrm{hi}$ & S \\
\hline PIM-035 & $4,31 \mathrm{~m}$ & $79,5 \mathrm{kl}$ & S \\
\hline PIM-036 & $3,3 \mathrm{j}$ & $59,9 \mathrm{ij}$ & $\mathrm{S}$ \\
\hline PIM-037 & $4,6 \mathrm{~m}$ & 83,41 & $\mathrm{~S}$ \\
\hline Linha-017 & $3,9 \mathrm{kl}$ & $72,1 \mathrm{k}$ & $\mathrm{S}$ \\
\hline 'Carolina Wonder' & $3,2 \mathrm{ij}$ & $58,1 \mathrm{ij}$ & S \\
\hline 'Charleston Belle' & $1,4 \mathrm{~d}$ & $26,0 \mathrm{~d}$ & LR \\
\hline PIX-022I-31-07-01 & $2,5 \mathrm{~g}$ & $46,4 \mathrm{~g}$ & LR \\
\hline PIX-022I-31-07-02 & $1,2 \mathrm{~cd}$ & $22,7 \mathrm{c}$ & MoR \\
\hline PIX-022I-31-13-01 & $0,7 \mathrm{a}$ & $13,7 \mathrm{a}$ & MoR \\
\hline PIX-022I-31-13-02 & $2,5 \mathrm{~g}$ & $46,8 \mathrm{~g}$ & LR \\
\hline PIX-022I-31-14-01 & $3,4 \mathrm{j}$ & $61,5 \mathrm{j}$ & S \\
\hline PIX-022I-31-14-02 & $2,0 \mathrm{f}$ & $36,3 \mathrm{f}$ & LR \\
\hline PIX-022I-31-20-01 & $1,6 \mathrm{e}$ & $30,4 \mathrm{e}$ & LR \\
\hline PIX-022I-31-20-02 & $1,7 \mathrm{e}$ & $31,8 \mathrm{e}$ & LR \\
\hline
\end{tabular}

${ }^{(1)}$ Médias seguidas de letras iguais, nas colunas e no mesmo experimento, não diferem entre si pelo teste de Duncan, a $5 \%$ de probabilidade. ${ }^{(2)}$, cultura suscetível (acima de 50\% de reprodução em relação ao tomate TOM-584); LR, levemente resistente (26 a 50\%); MoR, moderadamente resistente (11 a 25\%); MR, muito resistente (1 a 10\%); e AR, altamente resistente (menos de 1\%), segundo Taylor (1967). ${ }^{(3)}$ Testemunha, tomateiro suscetível a M. incognita e M. javanica. ${ }^{(4)}$ Testemunha portadora do gene Mi (resistente a M. incognita e M. javanica).

M. incognita esteja associada à menor suscetibilidade a M. enterolobii, isso não se revelou verdadeiro para as cultivares Talismã e Ouro Negro, o que provavelmente indica genes distintos no controle da resistência do feijão a diferentes espécies de Meloidogyne. No presente trabalho, somente a cultivar Aporé pode ser considerada como potencial fonte de resistência a M. enterolobii.

Em geral, a alface não mostrou-se boa hospedeira a $M$. enterolobii, pois todas as cultivares avaliadas apresentaram pelo menos resistência moderada ao nematoide (Tabela 1). As cultivares Julia, Hortência, Verônica, Grand Rapids e Babá de Verão foram consideradas muito resistentes, conforme a escala de Taylor (1967). A cultivar Grand Rapids também é resistente a $M$. incognita e $M$. javanica, e o controle genético, tanto para $M$. incognita (Gomes et al., 2000) quanto para M. javanica (Maluf et al., 2002), é feito por um único loco gênico com efeito predominantemente aditivo e herdabilidade no sentido amplo relativamente alta. A cultivar Salinas 88, considerada resistente a M. incognita (Carvalho Filho et al., 2008; Silva et al., 2008), mostrou-se apenas moderadamente resistente a M. enterolobii.

Entre os genótipos de batata-doce, as cultivares Brazlândia Branca e Brazlândia Rosada foram suscetíveis a $M$. enterolobii (Tabela 1). Resultados semelhantes foram observados por Marchese et al. (2010) para $M$. incognita raça 1. As cultivares Brazlândia Roxa e Palmas, embora caracterizadas como resistentes a $M$. incognita raça 1 (Marchese et al., 2010), foram suscetíveis a $M$. enterolobii. Os clones UFLA07-49 e UFLA07-53 foram classificados como muito resistentes a $M$. enterolobii, como também observado por Marchese et al. (2010) para M. incognita raça 1. No presente trabalho, o clone UFLA07-43, 
considerado imune à raça 1 de $M$. incognita, foi suscetível a $M$. enterolobii. Esse comportamento é mais um indício de que a resistência a diferentes espécies ou raças de Meloidogyne deve ser mediada por genes diferentes.

Apesar de todos os genótipos de Capsicum avaliados terem apresentado índices de reprodução acima de $10 \%$, houve diferença significativa entre os tratamentos (Tabela 1). As cultivares Carolina Wonder e Charleston Belle são homozigotas para o alelo dominante $N$, que controla a resistência às espécies $M$. incognita, $M$. javanica e $M$. arenaria (Thies \& Fery, 2000); porém, não foram resistentes a M. enterolobii, com índices de reprodução acima de $25 \%$. Brito et al. (2007) reportaram a patogenicidade de $M$. enterolobii a 'Charleston Belle' e às linhagens 9913/2, SAIS 97.9001 e SAIS 97.9008, portadoras do gene Tabasco. Os resultados do presente trabalho, associados aos obtidos por Brito et al. (2007), indicam que a utilização do gene $N$ seria pouco efetiva no sentido de promover bons níveis de resistência a M. enterolobii, em pimentão.

Os acessos de pimenta $C$. chinense BGH-433 e BGH-4285 apresentaram índices de reprodução abaixo de $25 \%$, em geral menores que os de $C$. annuum (Tabela 1), e estão entre as melhores fontes de resistência a $M$. enterolobii, entre os acessos avaliados. Essa resistência moderada a $M$. enterolobii não parece estar associada à resistência a $M$. incognita, pois BGH-433 (resistente a M. incognita) e BGH-4285 (suscetível) apresentaram graus semelhantes de resistência a $M$. enterolobii. Resultados similares foram obtidos por Oliveira (2007) que, ao avaliar diferentes espécies do gênero Capsicum, observou que todos os nove genótipos de $C$. chinense foram suscetíveis a $M$. enterolobii, com fatores de reprodução de 2,74 a 12,62 , menores que os obtidos em $C$. annuиm, no mesmo experimento, no qual somente o genótipo de C. frutescens foi considerado resistente. Os híbridos comerciais de pimentão Magali-R, Magnata Super e Mayara F1 tiveram índices de reprodução acima de $70 \%$ e foram considerados suscetíveis a M. enterolobii. Cirotto et al. (2007) também classificaram Magali-R como suscetível a $M$. enterolobii e $M$. incognita. Os genótipos PIX-022I-31-07-01, PIX-022I-31-07-02, P IX-022 I-3 1- 13 -01, P IX-02 2 I-31-13-02, PIX-022I-31-14-01, PIX-022I-31-14-02, PIX-022I-31-20-01, PIX-022I-31-20-02, com índices de reprodução entre 13,7 e $61,5 \%$, foram classificados como levemente ou moderadamente resistentes a M. enterolobii, com exceção de PIX-022I-31-14-01. Embora todos esses acessos sejam originários da população PIX-022E, e tenham sido previamente selecionados quanto à resistência a $M$. incognita (Freitas et al., 2000), sua homozigose com relação à presença do alelo $\mathrm{Me}-3$, que confere resistência a M. incognita e M.javanica, não está comprovada.Assim, o comportamento anômalo de PIX-022I-31-14-01 não é inesperado. O grau leve a moderado de resistência a $M$. enterolobii mostrado pelas demais linhagens PIX-022I parece indicar que o gene $\mathrm{Me}-3$ pode ser efetivo em conferir pelo menos um leve grau de resistência a esse nematoide.

\section{Conclusões}

1. Todos os genótipos de tomate avaliados são suscetíveis a Meloidogyne enterolobii.

2. A cultivar de feijão Aporé, as cultivares de alface Julia, Hortência, Verônica, Grand Rapids e Babá de Verão, os acessos de Capsicum chinense BGH-433 e BGH-4285, os acessos de C. annuum PIM-031, PIX-022I-31-07-02 e PIX-022I-31-13-01, e os clones de batata-doce UFLA07-49 e UFLA-07-53 são fontes promissoras de resistência a $M$. enterolobii.

3. A resistência a $M$. enterolobii aparentemente é mediada por genes diferentes dos que conferem resistência a outras espécies e raças de Meloidogyne.

\section{Agradecimentos}

À Fundação de Amparo à Pesquisa do Estado de Minas Gerais, ao Conselho Nacional de Desenvolvimento Científico e Tecnológico, à Coordenação de Aperfeiçoamento de Pessoal de Nível Superior, à Universidade Federal de Lavras, à Fundação de Apoio ao Ensino, Pesquisa e Extensão, à Fundação de Desenvolvimento Científico e Cultural, e à Hortiagro Sementes, pelo apoio.

\section{Referências}

BITENCOURT, N.V.; SILVA, G.S. Reprodução de Meloidogyne enterolobii em olerícolas. Nematologia Brasileira, v.34, p.181-183, 2010.

BONETTI, J.I.S.; FERRAZ, S. Modificações do método de Hussey \& Barker para extração de ovos de Meloidogyne exigua em raízes de cafeeiro. Fitopatologia Brasileira, v.6, p.553-561, 1981.

BRITO, J.A.; STANLEY, J.D.; KAUR, R.; CETINTAS, R.; DI VITO, M.; THIES, J.A.; DICKSON, D.W. Effects of the Mi-1, N 
and Tabasco genes on infection and reproduction of Meloidogyne mayaguensis on tomato and pepper genotypes. Journal of Nematology, v.39, p.327-332, 2007.

CAMPOS, V.P.; CAMPOS, J.R.; SILVA, L.H.C.P.; DUTRA, M.R. Manejo de nematóides em hortaliças. In: SILVA, L.H.C.P. da; CAMPOS, J.R. (Ed.).; NOJOSA, G.B. de A. Manejo integrado: doenças e pragas em hortaliças. Lavras: UFLA, 2001. p.125-158.

CANTU, R.R.; WILCKEN, S.R.S.; ROSA, J.M.O.; GOTO, R. Reação de porta-enxertos comerciais de tomateiro a Meloidogyne mayaguensis. Summa Phytopathologica, v.35, p.216-218, 2009.

CARNEIRO, R.G.; MÔNACO, A.P. do A.; MORITZ, M.P.; NAKAMURA, K.C.; SCHERER, A. Identificação de Meloidogyne mayaguensis em goiabeira e em plantas invasoras, em solo argiloso, no Estado do Paraná. Nematologia Brasileira, v.30, p.293-298, 2006a.

CARNEIRO, R.M.D.G.; ALMEIDA, M.R.A.; BRAGA, R.S.; ALMEIDA, C.A. de; GLORIA, R. Primeiro Registro de Meloidogyne mayaguensis parasitando plantas de tomate e pimentão resistentes à meloidoginose no estado de São Paulo. Nematologia Brasileira, v.30, p.81-86, 2006 b.

CARVALHO FILHO, J.L.S. de; GOMES, L.A.A.; WESTERICH, J.N.; MALUF, W.R.; CAMPOS, V.C.; FERREIRA, S. Inheritance of resistance of 'Salinas 88' lettuce to the root-knot nematode Meloidogyne incognita (Kofoid \& White) Chitwood. Revista Brasileira de Agrociência, v.14, p.279-289, 2008.

CETINTAS, R.; KAUR, R.; BRITO, J.A.; MENDES, M.L.; NYCZEPIR A.P.; DICKSON, D.W. Pathogenicity and reproductive potential of Meloidogyne mayaguensis and M.floridensis compared with three common Meloidogyne spp. Nematropica, v.37, p.21-31, 2007.

CIROTTO, P.A.; RESENDE, F.O.; QUINTANILHA, A.P.; CARNEIRO, R.M.D.G. Resistência de cultivares de Capsicum annum a Meloidogyne spp. Brasília: Embrapa Recursos Genéticos e Biotecnologia, 2007. 12p. (Embrapa Recursos Genéticos e Biotecnologia. Boletim de pesquisa e desenvolvimento, 100).

DEVRAN, Z.; SOGUT, M.A.; MUTLU, N. Response of tomato rootstocks with the Miresistance gene to Meloidogyne incognita race 2 at different soil temperatures. Phytopathologia Mediterranea, v.49, p.11-17, 2010.

FERREIRA, S.; GOMES, L.A.A.; MALUF, W.R.; CAMPOS, V.P.; CARVALHO FILHO, J. L.S.; SANTOS, D.C. Resistance of dry bean and snap bean cultivars to root-knot nematodes. HortScience, v.45, p.320-322, 2010.

FREITAS, J.A. de; AZEVEDO, S.M. de; MALUF, W.R.; GOMES, L.A.A.; SILVA, J.A.R. da. Reação de progênies de pimentão à infecção por Meloidogyne incognita, raças 1 e 3. Acta Scientiarum. Agronomy, v.22, p.925-930, 2000.
GOMES, L.A.A.; MALUF, W.R.; CAMPOS, V.P. Inheritance of the resistant reaction of the lettuce cultivar 'Grand Rapids' to the southern root-knot nematode Meloidogyne incognita (Kofoid \& White) Chitwood. Euphytica, v.114, p.37-46, 2000.

GUIMARÃES, L.M.P.; MOURA, R.M. de; PEDROSA, E.M.R. Parasitismo de Meloidogyne mayaguensis em diferentes espécies botânicas. Nematologia Brasileira, v.27, p.139-145, 2003.

HUSSEY, R.S.; BARKER, K.R. A comparison of methods of collecting inocula of Meloidogyne spp. including a new technique. Plant Disease Reporter, v.57, p.1025-1028, 1973.

MALUF, W.R.; AZEVEDO, S.M.; GOMES, L.A.A.; OLIVEIRA, A.C.B. de. Inheritance of resistance to the root-knot nematode Meloidogyne javanica in lettuce. Genetics and Molecular Research, v.1, p.64-71, 2002.

MARCHESE, A.; MALUF, W.R.; GONÇALVES NETO, A.C.; GONÇALVES, R.J. de S.; GOMES, L.A.A. Seleção de clones de batata-doce resistentes a Meloidogyne incognita raça 1. Pesquisa Agropecuária Brasileira, v.45, p.997-1004, 2010.

OLIVEIRA, D.C. Enxertia de plantas de pimentão em Capsicum spp. no manejo de nematóides de galha. 2007. 134p. Tese (Doutorado) - Universidade Estadual Paulista, Jaboticabal.

PINHEIRO, J.B.; BOITEUX, L.S.; LOPES, C.A.; SILVA, G.O. da. Identificação de fontes de resistência ao nematóide Meloidogyne mayaguensis em acessos de tomateiro (Solanum secção Lycopersicon). Brasília: Embrapa Hortaliças, 2009. 18p. (Embrapa Hortaliças. Boletim de pesquisa e desenvolvimento, 56).

SAS INSTITUTE. SAS/STAT software: changes and enhancements. Release 8. Cary: SAS Institute, 2001.

SILVA, R.R.; GOMES, L.A.A.; MONTEIRO, A.B.; MALUF, W.R.; CARVALHO FILHO, J.L.S. de; MASSAROTO, J.A. Linhagens de alface-crespa para o verão resistentes ao Meloidogyne javanica e ao vírus mosaico-da-alface. Pesquisa Agropecuária Brasileira, v.43, p.1349-1356, 2008.

TAYLOR, A.L. Introduction to research on plant nematology: an FAO guide to the study and control of the plant-parasitic nematodes. Rome: Food and Agricultural Organization of the United Nations, 1967. 133p.

THIES, J.A.; FERY, R.L. Characterization of resistance conferred by the $\mathrm{N}$ gene to Meloidogyne arenaria races 1 and 2, M. hapla, and $M$. javanica in two sets of isogenic lines of Capsicum annuum $\mathrm{L}$. Journal of the American Society for Horticultural Science, v.125, p.71-75, 2000.

WILLIAMSON, V.M. Root-knot nematode resistance genes in tomato and their potential for future use. Annual Review of Phytopathology, v.36, p.277-293, 1998.

YANG, B.J.; EISENBACK, J.D. Meloidogyne enterolobii n. sp. (Meloidogynidae), a root-knot nematode parasitizing pacara earpod tree in China. Journal of Nematology, v.15, p.381-391, 1983.

Recebido em 11 de abril de 2011 e aprovado em 12 de agosto de 2011 